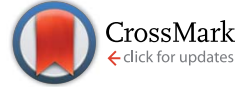

Cite this: RSC Adv., 2015, 5, 95817

Received 31st July 2015

Accepted 30th October 2015

DOI: 10.1039/c5ra22152h

www.rsc.org/advances

\title{
Gold nanoparticles are suitable cores for building tunable iminosugar multivalency $\dagger$
}

\author{
C. Matassini, ${ }^{\text {ab } M . ~ M a r r a d i, t^{* b c}}{ }^{\text {F. Cardona, }}{ }^{a}$ C. Parmeggiani, ${ }^{\text {ad }}$ I. Robina, ${ }^{e}$ \\ A. J. Moreno-Vargas, ${ }^{\text {e S. Penadés }}{ }^{\mathrm{bc}}$ and A. Goti ${ }^{\star a}$
}

The first example of iminosugars multimerization based on gold nanoparticle cores was achieved by a straightforward synthetic strategy based on the use of simple glycosides of $\alpha$-D-mannose or $\beta$-Dglucose to modulate the density of biologically active pyrrolizidine and piperidine iminosugars at the gold surface. Exceptionally small and water dispersible gold colloids were obtained by self assembly of thiol ending sugar and novel iminosugar conjugates on the surface of in situ forming gold nanoparticles. The resulting nanostructures were characterized by different techniques. Preliminary screenings demonstrated that the novel nanosized architectures retain their bioactivity and make possible its modulation.

\section{Introduction}

Iminosugars are excellent tools for the exploration of glycosidase inhibition. ${ }^{1}$ Glycosidase inhibitors have several biomedical applications for the treatment of different pathologies ranging from bacterial and viral infections, diabetes (e.g. Glyset) and genetic metabolic disorders (e.g. Zavesca). ${ }^{2}$ The total synthesis of natural iminosugars and their analogues is rather challenging due to the presence of numerous stereocenters. Synthetic chemists have developed different approaches, either starting from the chiral pool or through enantioselective syntheses. ${ }^{3}$ Some of us have been involved in the total synthesis of such compounds for several years, mainly exploiting carbohydrate derived nitrones as key building blocks in 1,3-dipolar cycloadditions or in organometallic additions. ${ }^{4}$ Recently, the presentation of iminosugars in a multimeric fashion onto a common scaffold has become a rather hot topic of research with the aim of constructing multivalent glycosidase inhibitors. ${ }^{5}$ The multivalent effect is defined as the affinity enhancement of a monovalent bioactive molecule towards its receptor

aDipartimento di Chimica "Ugo Schiff", Università di Firenze, Via della Lastruccia 3-13, 50019 Sesto Fiorentino, FI, Italy. E-mail: andrea.goti@unifi.it

${ }^{b}$ CIC biomaGUNE, Biofunctional Nanomaterials Unit, Lab. GlycoNanoTechnology, P. Miramón 186, San Sebastián, Spain. E-mail:m.marradi@cidetec.es

'CIBER-BBN, P. Miramón 186, 20009 San Sebastián, Spain

${ }^{d}$ CNR - INO and LENS, via N. Carrara 1, 50019 Sesto Fiorentino, FI, Italy

${ }^{e}$ Departamento de Quimica Orgánica, Facultad de Quimica, Universidad de Sevilla, Prof. García González 1, E-41012, Sevilla, Spain

$\dagger$ Electronic supplementary information (ESI) available: Synthesis, characterization, NMR, TEM, UV-vis spectra of new compounds, details for biological tests and graphics of $\mathrm{IC}_{50}$ of active compounds towards amyloglucosidase. See DOI: 10.1039/c5ra22152h

‡ Present address: IK4-CIDETEC, Biomaterials Unit, P. Miramón 196, San Sebastián, Spain. consequent to multimerization. ${ }^{6,7}$ It has been extensively investigated in carbohydrate-lectin interactions, ${ }^{6 a, f, g}$ where multiple binding sites are present in the receptors. However, during the last five years evidence for the implication of a multivalent effect even for iminosugar-glycosidase interactions have been collected. High avidity was reached with synthetic multivalent iminosugars with some glycosidases of therapeutic interest. ${ }^{8}$ Concerning glycosidase inhibition, a statistical rebinding effect is likely to occur since glycosidases have a single binding site, albeit other factors cannot be excluded. ${ }^{5}$ After the first report describing a significant inhibition enhancement towards jack-bean $\alpha$-mannosidase with a trivalent iminosugar, ${ }^{9}$ different examples of scaffolds have been reported for the creation of multivalent iminosugar architectures, ranging from simple dendrimers, ${ }^{8 c-e, 10}$ to cyclodextrins, ${ }^{8 b, c, e, 11}$ fullerenes, ${ }^{8 a, 12}$ calixarenes ${ }^{8 c, 13}$ To date, the most common synthetic approach to multivalent iminosugars uses the copper-mediated azide-alkyne cycloaddition (CuAAC) as the key step, that has inherent drawbacks connected with possible contamination of the final compounds by traces of the metal catalyst. ${ }^{5 b}$

We envisaged that gold glyconanoparticles (sugar-coated gold nanoparticles, Au-GNPs) $)^{14}$ could be excellent novel scaffolds for a copper-free multimerization of bioactive iminosugars. Indeed, Au-GNPs combine a good stability of the colloidal system in water and cell permeability thanks to their carbohydrate shell and are readily assembled through one-pot insertion of the active ligand(s) while creating the gold nanoparticles themselves. ${ }^{14 a, 15}$ Moreover, evidence that sugars tailored onto GNPs are more resistant to glycosidase cleavage, ${ }^{16}$ joined to possible simultaneous grafting of different ligands to the gold core, prompted us to employ simple monosaccharides as inner components and iminosugars as active ones in order to achieve 
our goal and target glycosidase inhibition. The planned synthetic method is expected to afford biocompatible nanoparticles with a very small size (gold core $<2 \mathrm{~nm}$ ), enabling the simultaneous grafting of several iminosugar ligands onto their small surface, thus reaching high local concentrations of the bioactive molecule.

Furthermore, this approach would lead to multivalent iminosugars with a tunable density, simply by varying the ratio among the inner component (the carbohydrate ligand) and the active component (the iminosugar ligand). ${ }^{\mathbf{1 7}, 18}$ This aspect is particularly crucial concerning glycosidase inhibition since the exact role of valency has not been totally understood (not always the highest valency corresponds to the highest multivalent effect). We report herein preliminary results of this study as a proof of concept demonstration.

\section{Results and discussion}

Au-GNPs consist of self-assembled monolayers (SAMs) of thiolending neoglycoconjugates bound to the metal surface by Au-S bonds. ${ }^{19}$ Then, we explored first the conjugation of selected iminosugars with a proper thiol-ending linker (Scheme 1). Among the biologically active iminosugars available in our laboratories, we selected pyrrolizidine $1^{10 a}$ and piperidine $2,{ }^{20}$ both bearing an amino moiety suitable for functionalization with a bifunctional linker ending with a thiol group through an appropriate reacting group at the other terminus (-NCS, linker 4; $-\mathrm{COOH}$, linker 7). We estimated this position as the most suitable to our aims, since the sugar mimic portion of the compounds responsible for recognition of the enzyme binding site is unaltered. Additionally, we already collected evidence that the biological response was not affected by structural variation at $\mathrm{C}-7$ of the pyrrolizidine iminosugar. ${ }^{10 a}$

On the basis of previous finding ${ }^{21}$ we chose a long and amphiphilic linker to impart flexibility and assist the water dispersibility of the whole nanoparticle. We firstly investigated the conjugation of the amino derivatives $\mathbf{1}$ and $\mathbf{2}$ with the linker 4 bearing an isothiocyanate group, obtained in three steps from the commercially available alcohol 3 in 54\% overall yield (Scheme 1). ${ }^{22}$ Formation of the thiourea linkages, a wellestablished reaction in bioconjugation, was performed in $\mathrm{MeOH}$ at room temperature and gave the adducts 5 and $\mathbf{6}$ in satisfactory yield after purification and deprotection with NaOMe (72\% and 56\%, respectively, over two steps). Unfortunately, the GNPs subsequently synthesized with these conjugates were not dispersible in water, even after vigorous stirring and/or addition of different acids (AcOH, TFA, $\mathrm{HCl})$ to yield the iminosugar ammonium salts.

In order to bypass this impasse, alternative biocompatible amide coupling was taken into account. The coupling of iminosugar derivatives 1 and 2 with carboxylic acid $7,{ }^{23}$ easily synthesized by Jones oxidation of alcohol 3, afforded conjugates 8 and 9 under different coupling conditions (Scheme 1). The use of 1-hydroxybenzotriazole (HOBt) and $O$-(benzotriazol-1-yl)$N, N, N^{\prime}, N^{\prime}$-tetramethyluronium hexafluorophosphate (HBTU) as coupling agents in dimethylformamide (DMF) at rt gave 8 in $51 \%$ yield. These conditions failed in the synthesis of the piperidine analogue 9. Instead, this compound was obtained in $89 \%$ yield using 1-ethyl-3-(3-dimethylaminopropyl)carbodiimide (EDC) as coupling agent in dimethylsulfoxide (DMSO). The amide conjugates $\mathbf{8}$ and $\mathbf{9}$ were completely characterized, while the corresponding deacetylated compounds 8a and 9a (Scheme 2A) were directly employed in the GNPs synthesis without further purification to prevent their oxidation to the corresponding disulfides (see below). The inner component ligands, namely 5-mercaptopent-1-yl $\beta$-D-glucopyranoside $\left(\beta_{G^{\prime} C_{5}} \mathrm{~S}, 10\right)$ and 5-mercaptopent-1-yl $\alpha$-D-mannopyranoside $\left(\alpha \mathrm{ManC}_{5} \mathrm{~S}, 11\right)$ (Scheme $\left.2 \mathrm{~B}\right)$ were prepared following a wellestablished protocol. ${ }^{21 a, 24}$ With the thiol-ending ligands 8a-9a<smiles>OC[C@H]1[C@H](O)[C@@H](O)C2C[C@@H](NC(=S)NCCOCCCCS)CN21</smiles><smiles>N[C@H]1C[C@@H]2[C@@H](O)[C@H](O)[C@H](CO)N2C1</smiles><smiles>CC(C)(C)C</smiles><smiles>C[As]CCC(C)(C)OCCOCC(=O)N[C@H]1CC2[C@@H](O)[C@H](O)[C@@H](CO)N2C1</smiles>

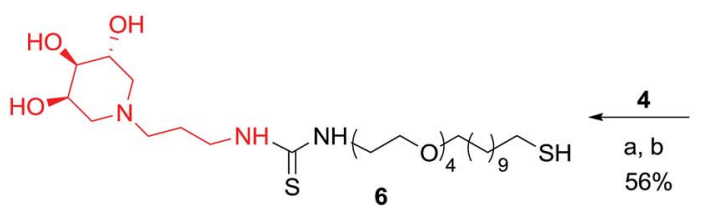<smiles>NCCCN1C[C@H](O)[C@@H](O)[C@H](O)C1</smiles>
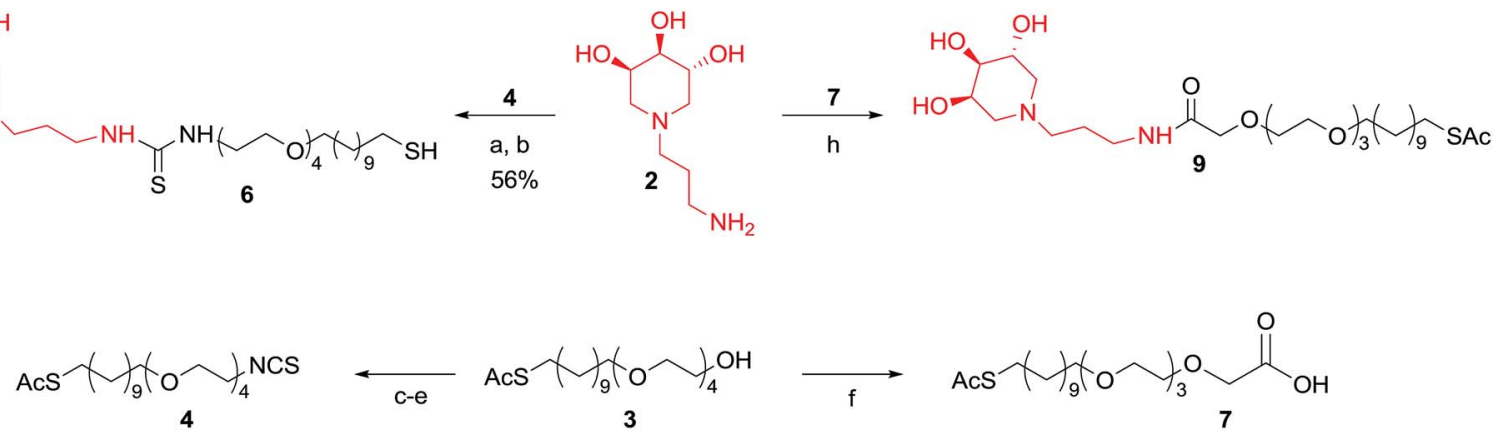

Scheme 1 Different approaches for the conjugation of iminosugars 1 and 2 to the thiol-ending linker. Reagents and reaction conditions: (a) $\mathrm{MeOH}, \mathrm{rt}, 18 \mathrm{~h}$; (b) $\mathrm{NaOMe}, \mathrm{MeOH}, \mathrm{rt}, 8 \mathrm{~h}$; (c) $\mathrm{PPh}_{3}, \mathrm{CBr}_{4}, \mathrm{CH}_{2} \mathrm{Cl}_{2}, \mathrm{rt}, 10 \mathrm{~min}, 80 \%$; (d) $\mathrm{NaN}_{3}, \mathrm{DMF}, \mathrm{rt}, 14 \mathrm{~h}$; (e) $\mathrm{PPh}_{3}, \mathrm{CS}_{2}, \mathrm{toluene}, 50{ }^{\circ} \mathrm{C}, 16 \mathrm{~h}, 68 \%$; (f) acetone, Jones reagent, rt, 20 min, 69\%; (g) HBTU, HOBt, DIPEA, DMF, rt, 15 h, 51\%; (h) EDC, HOBt, DIPEA, DMSO, Ar, rt, 65 h, 89\%. 
A) Active component thiol-ending ligands<smiles>CC(C)(C)OCCOCC(=O)NC1C[C@H]2[C@@H](O)[C@H](O)[C@@H](CO)N2C1</smiles><smiles>CC(C)CCCN1C[C@H](O)[C@@H](O)[C@H](O)C1</smiles>

B) Inner component thiol-ending ligands

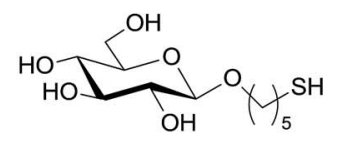

$\beta \mathrm{GlcC}_{5} \mathrm{~S}, 10$

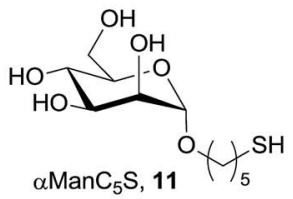

C) Iminosugar based Au-GNPs

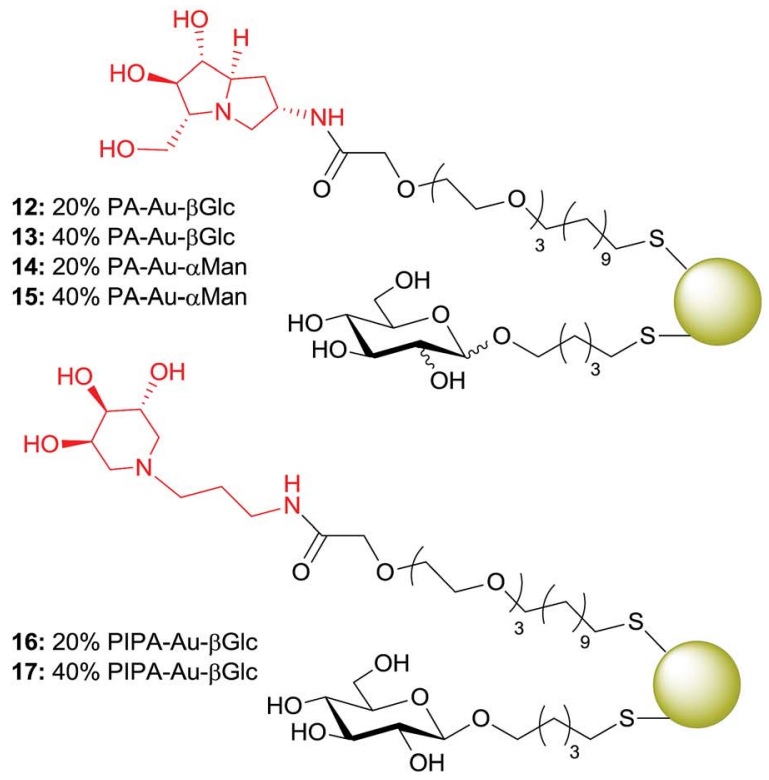

D) $100 \%$ sugar based Au-GNPs

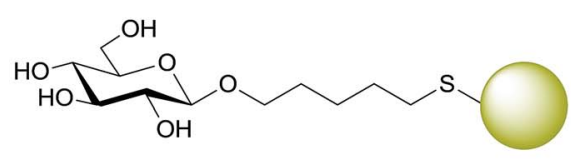

18: Au- $\beta$ Glc

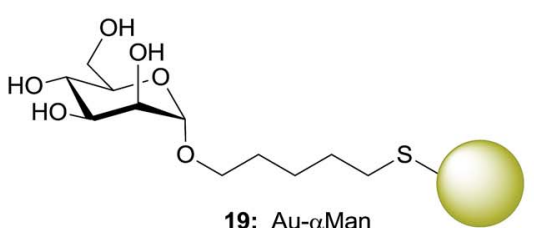

19: Au- $\alpha$ Man

Scheme 2 (A) Pyrrolizidine and piperidine based thiol-ending ligands (active components); (B) $\beta$-D-glucose and $\alpha$-D-mannose based thiolending ligands (inner components); (C) new synthesized Au-GNPs with different active components, inner components and densities; (D) 100\% $\beta$-glucose (Au- $\beta$ Glc) and $100 \% \alpha$-mannose (Au- $\alpha$ Man) Au-GNPs.

and 10-11 in hand, novel GNPs were prepared in a one-pot fashion by treating a water solution of $\mathrm{Au}(\mathrm{III})$ with a reducing agent with the presence of an excess of the desired ligands as reported below. Depending on the iminosugar based ligand employed as the active component, pyrrolizidine alkaloid PAGNPs or piperidine alkaloid PIPA-GNPs were obtained (Scheme 2C).

For the preparation of GNPs 12-17, iminosugar conjugates 8 and 9 were deacetylated to $\mathbf{8 a}$ and $\mathbf{9 a}$ which, without purification, were mixed in situ with $\beta \mathrm{GlcC}_{5} \mathrm{~S} \mathbf{1 0}$ or $\alpha \mathrm{ManC}_{5} \mathrm{~S} \mathbf{1 1}$ in the proper ratio, before adding the $\mathrm{Au}$ (III) solution and the reducing agent. Indeed, on purification through Sephadex 8a and 9a underwent complete oxidation to the corresponding disulfides. Conversely, $\beta \mathrm{GlcC}_{5} \mathrm{~S}$ and $\alpha \mathrm{ManC}_{5} \mathrm{~S}$ showed a lower tendency to oxygen-mediated oxidation, giving no more than $20 \%$ of the corresponding disulfides. Use of the purified ligands resulted in a lower incorporation of the iminosugar compared to the sugar ligands at gold surface, as attested by the ${ }^{1} \mathrm{H}$ NMR spectra performed before and after nanoparticle formation. This result is in agreement with the notion that formation of SAMs on gold from solutions of a thiol and a disulfide in mixture takes place with preferential adsorption of the thiol. ${ }^{25}$ On the other hand, when conjugates $\mathbf{8}$ and $\mathbf{9}$ were deacetylated under $\mathrm{Ar}$ atmosphere and immediately employed in the preparation of GNPs without further purification (see "General Procedure for the in situ deprotection of $S$-acetyl conjugates" in the ESI $\dagger$ ), the ratio between iminosugar and sugar ligands in solution was maintained on the gold cluster surface. In particular, the PA-Au GNPs were prepared by using $\beta \mathrm{GlcC}_{5} \mathrm{~S} 10$ (PA-Au- $\beta$ Glc, 12 and 13) or $\alpha \mathrm{ManC}_{5} \mathrm{~S} 11$ (PA-Au- $\alpha \mathrm{Man}, 14$ and 15) as inner component, in order to detect or rule out any additive or synergic inhibitory effect of the $\beta \mathrm{GlcC}_{5} \mathrm{~S}$ inner component towards $\beta$ glucosidases.

Conversely, due to the extreme selectivity of PIPA towards $\alpha$ L-fucosidases, ${ }^{20}$ only $\beta_{G_{l c C}} \mathrm{~S} \mathbf{1 0}$ was employed as inner component for GNPs 16 and 17.

In all cases, water dispersible and stable gold GNPs of $2 \mathrm{~nm}$ average diameter were obtained by adding an aqueous solution of tetrachloroauric acid $\left(\mathrm{HAuCl}_{4}\right)$ to a methanolic solution of a mixture of the thiol-derivatized conjugates ( 3 equiv. overall with respect to $\mathrm{HAuCl}_{4}$ ) in the desired proportion. The resulting mixture was reduced in situ with $\mathrm{NaBH}_{4}$ (27 equiv.) and the suspension was vigorously shaken for $2 \mathrm{~h}$ at $25^{\circ} \mathrm{C}$. The supernatant was removed, the nanoparticles were washed with methanol and the residue was dissolved in milliQ water, purified by dialysis and characterized by ${ }^{1} \mathrm{H}$ NMR spectroscopy, 
transmission electron microscopy (TEM), infrared (IR) and ultraviolet-visible (UV-vis) spectroscopies. Glyconanoparticles with different densities of active component ( $20 \%$ and $40 \%)$ were obtained varying the ratio of iminosugar conjugate to the sugar derivative chosen as inner component $\left(\beta_{\mathrm{GlcC}_{5} \mathrm{~S}} \mathbf{1 0}\right.$ or $\alpha \mathrm{ManC}_{5} \mathrm{~S} 11$ ) in the reacting mixture. Uniformity of the sugar/ iminosugar ligand ratio was ascertained by ${ }^{1} \mathrm{H}$ NMR in the reaction mixture and, after cluster formation, either in the supernatant and in the washings. Quantitative NMR (qNMR) of GNPs in deuterium oxide with 3-(trimethylsilyl)propionic2,2,3,3- $\mathrm{d}_{4}$ acid (TSP- $\mathrm{d}_{4}$ ) as an internal reference was also performed. The ${ }^{1} \mathrm{H}$ NMR spectra of the GNPs featured broader peaks compared to those of the corresponding free ligands. An example of iminosugar GNP characterization is shown in Fig. 1 for $40 \%$ PA-Au- $\alpha$-Man 15.

The synthesized GNPs showed an exceptionally small core (most in the 1-2 nm range), as demonstrated by TEM analysis. TEM micro-graphs showed uniform dispersion of the GNPs and no aggregation was evident. The UV/vis spectra were characterized by a surface plasmon band at around $520 \mathrm{~nm}$, except in the case of the smallest core-sized GNPs, for which the plasmon was barely visible. As mentioned above, all of the obtained GNPs are water dispersible and are stable for months (no flocculation) under physiological conditions at room temperature. Based on the gold core size (determined by TEM) average molecular formulas and the corresponding molecular weights were calculated by estimation of number of anchored ligands from the literature ${ }^{26}$ and the ligand ratio obtained from qNMR (see ESI†).

GNPs $100 \%$-functionalized with $\beta$-glucoside 10 (Au- $\beta$ Glc, 18) or $\alpha$-mannoside 11 (Au- $\alpha$ Man, 19) shown in Scheme $2 \mathrm{D}$ were also prepared as control systems, following a reported procedure. ${ }^{21 a}$
A)
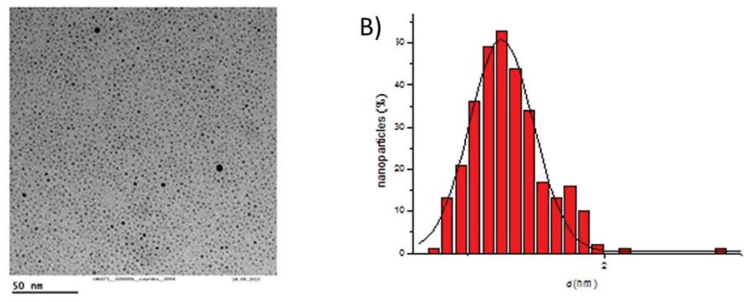

C)

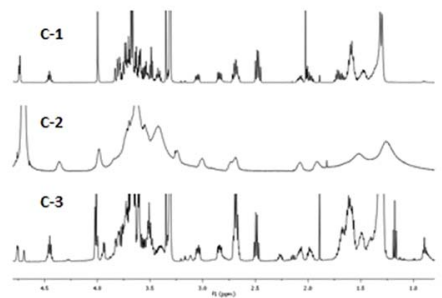

D)

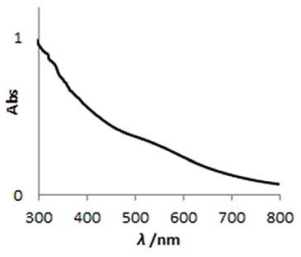

Fig. 1 Characterization of glyconanoparticles 15 (40\% PA-Au-Man): (A) TEM micrograph in $\mathrm{H}_{2} \mathrm{O}$; (B) size-distribution histogram obtained by measuring 300 nanoparticles (average diameter $1.2 \pm 0.2 \mathrm{~nm}$ ); (C) ${ }^{1} \mathrm{H}$ NMR $\left(\mathrm{D}_{2} \mathrm{O}\right)$ spectra of a $3: 2$ mixture of $\alpha \mathrm{ManC}_{5} \mathrm{~S}$ and derivative $8 \mathrm{a}$ before $(\mathrm{C}-1)$ and after ( $\mathrm{C}-3)$ GNP formation, and of the corresponding GNP 15 (C-2); (D) UV/vis spectrum.
Table 1 Inhibition of amyloglucosidase from Aspergillus niger (at 0.16 $\mathrm{mg} \mathrm{mL}^{-1}$ in terms of Au-GNP)

\begin{tabular}{llllc}
\hline Entry & GNP & $\begin{array}{l}\text { Effective active } \\
\text { component conc. }(\mu \mathrm{M})\end{array}$ & $\begin{array}{l}\text { \% of } \\
\text { inhibition }\end{array}$ & IC $_{50}(\mu \mathrm{M})$ \\
\hline 1 & $\mathbf{1 2}$ & 11 & $83 \%$ & 4.4 \\
2 & $\mathbf{1 3}$ & 29 & $91 \%$ & 8.3 \\
3 & $\mathbf{1 4}$ & 10 & $83 \%$ & 4.0 \\
4 & $\mathbf{1 5}$ & 38 & $90 \%$ & 13.9 \\
\hline
\end{tabular}

A preliminary biological evaluation towards a panel of eleven commercially available glycosidases (see ESI $\dagger$ for the complete set of inhibition data) disclosed promising results, especially for the inhibition of amyloglucosidase from Aspergillus niger. In particular, PA-GNPs afforded $\mathrm{IC}_{50}$ values in the low micromolar range (4.0-13.9 $\mu \mathrm{M}$, Table 1), calculated per iminosugar unit based on their evaluated density on the nanoparticles surface. Taking the $N$-acetyl derivative of $\mathbf{1}$ as the monovalent reference compound $\left(N\right.$-acetyl-1, $\left.{ }^{27} \mathrm{IC}_{50}=1.7 \mu \mathrm{M}\right)$, these results demonstrate that the inhibitory activity properties are retained in these multivalent architectures, besides displaying higher selectivity (see ESI $\dagger$ ).

As expected, the inner component $\left(\beta \mathrm{GlcC}_{5} \mathrm{~S}\right.$ or $\left.\alpha \mathrm{ManC}_{5} \mathrm{~S}\right)$ has no effect on the inhibitory activity, as demonstrated by the same $\mathrm{IC}_{50}$ values of GNPs 12 and $\mathbf{1 4}$ ( $c f$. entries 1 and 3, Table 1). Additionally, compounds 18 and 19 did not show any inhibition towards amyloglucosidases at $0.16 \mathrm{mg} \mathrm{mL}^{-1}$ (see ESI†े).

Interestingly, $\mathrm{IC}_{50}$ increased with the concentration of the active component (entries 2 and 4 vs. 1 and 3, Table 1), showing that the density of the active component is a crucial parameter. Once again, this result suggests that increasing the multivalency of iminosugars over a certain limit is not beneficial for bioactivity. ${ }^{18}$

\section{Conclusions}

We have reported the first examples of iminosugars multimerization on gold nanoparticles. Au-GNPs consisting of a nanometric gold core bearing selected iminosugar derivatives at different densities as active components and simple monosaccharides as inner components were prepared by a straightforward click approach. The novel Au-GNPs were characterized by different techniques. It is worthy to note that this approach represents one of a very few examples of copper free methods for the synthesis of multivalent iminosugars, an added value for biological applications. Preliminary biological assays towards commercially available purified enzymes were encouraging, showing inhibition in the low micromolar range towards amyloglucosidase. Further experiments are currently underway with more relevant human enzymes as well as cellular systems, to check whether the capacity of easy internalization of GNPs into cells can reduce the minimal dose of iminosugar required to significantly inhibit targeted enzymes. These new nanosystems decorated with different iminosugars may also serve as useful tools for studying molecular mechanisms yet to be fully elucidated. 


\section{Acknowledgements}

We thank MIUR-Italy (PRIN 2010-2011, 2010L9SH3K 006), Ministero della Salute/Regione Toscana (Ricerca Finalizzata, RF-2011-02347694), MINECO (Spain, CT2011-27268) and the Ministerio de Economía y Competitividad (Spain, CTQ 201231247) for financial support. CM thanks Ente Cassa di Risparmio di Firenze (2013/0366) for a fellowship and the Basque Department of Economical Development and Competitiveness for co-financing her PhD fellowship.

\section{Notes and references}

1 (a) A. E. Stütz and T. M. Wrodnigg, Adv. Carbohydr. Chem. Biochem., 2011, 66, 187; (b) T. M. Gloster and G. J. Davies, Org. Biomol. Chem., 2010, 8, 305.

2 (a) P. Compain and O. R. Martin, Iminosugars: from Synthesis to Therapeutic Applications, Wiley VCH, New York, 2007; (b) G. Horne, F. X. Wilson, J. Tinsley, D. H. Williams and R. Storer, Drug Discovery Today, 2011, 16, 107; (c) G. Horne and F. X. Wilson, Prog. Med. Chem., 2011, 50, 135; (d) R. J. Nash, A. Kato, C.-Y. Yu and G. W. J. Fleet, Future Med. Chem., 2011, 3, 1513.

3 (a) T. Ayad, Y. Genisson and M. Baltas, Curr. Org. Chem., 2004, 8, 1211; (b) K. Afarinkia and A. Bahar, Tetrahedron: Asymmetry, 2005, 16, 1239; (c) M. S. M. Pearson, M. MathéAllainmat, V. Fargeas and J. Lebreton, Eur. J. Org. Chem., 2005, 2159; (d) B. G. Davis, Tetrahedron: Asymmetry, 2009, 20, 652; (e) I. Dragutan, V. Dragutan and A. Demonceau, RSC Adv., 2012, 2, 719.

4 Selected papers: (a) A. Brandi, F. Cardona, S. Cicchi, F. M. Cordero and A. Goti, Chem.-Eur. J., 2009, 15, 7808; (b) F. Cardona, A. Goti, C. Parmeggiani, P. Parenti, M. Forcella, P. Fusi, L. Cipolla, S. M. Roberts, G. J. Davies and T. M. Gloster, Chem. Commun., 2010, 46, 2629; (c) D. Martella, F. Cardona, C. Parmeggiani, F. Franco, J. A. Tamayo, I. Robina, E. Moreno-Clavijo, A. J. MorenoVargas and A. Goti, Eur. J. Org. Chem., 2013, 4047; (d) P. Merino, I. Delso, T. Tejero, F. Cardona, M. Marradi, E. Faggi, C. Parmeggiani and A. Goti, Eur. J. Org. Chem., 2008, 2929; (e) C. Parmeggiani, F. Cardona, L. Giusti, H.-U. Reissig and A. Goti, Chem.-Eur. J., 2013, 19, 10595.

5 For reviews, see: (a) P. Compain and A. Bodlenner, ChemBioChem, 2014, 15, 1239; (b) A. Marra, P. Dumy, R. Zelli and J.-F. Longevial, New J. Chem., 2015, 39, 5050; (c) S. G. Gouin, Chem.-Eur. J., 2014, 20, 11616.

6 (a) J. J. Lundquist and E. J. Toone, Chem. Rev., 2002, 102, 555; (b) C. Fasting, C. A. Schalley, M. Weber, O. Seitz, S. Hecht, B. Koksch, J. Dernedde, C. Graf, E.-W. Knapp and R. Haag, Angew. Chem., Int. Ed., 2012, 51, 10472; (c) S.-K. Choi, in Synthetic Multivalent molecules: concepts and biomedical applications, John Wiley \& Sons, Inc., Hoboken, New Jersey, 2004; (d) L. L. Kiessling, J. E. Gestwicki and L. E. Strong, Angew. Chem., Int. Ed., 2006, 45, 2348; (e) D. Deniaud, K. Julienne and S. G. Gouin, Org. Biomol. Chem., 2011, 9, 966; $(f)$ R. T. Lee and Y. C. Lee, Glycoconjugate J., 2000, 17,
543; $(g)$ T. K. Dam and C. F. Brewer, Adv. Carbohydr. Chem. Biochem., 2010, 63, 139.

7 T. K. Lindhorst, Multivalent Glycosystems for Nanoscience, Beilstein J. Org. Chem., 2014, 10.

8 Selected papers: (a) P. Compain, C. Decroocq, J. Iehl, M. Holler, D. Hazelard, T. Mena Barragán, C. Ortiz Mellet and J.-F. Nierengarten, Angew. Chem., Int. Ed., 2010, 49, 5753; (b) C. Decroocq, D. Rodríguez-Lucena, V. Russo, T. Mena Barragán, C. Ortiz Mellet and P. Compain, Chem.Eur. J., 2011, 17, 13825; (c) Y. Brissonet, C. Ortiz Mellet, S. Morandat, M. I. Garcia Moreno, D. Deniaud, S. E. Matthews, S. Vidal, S. Šesták, K. El Kirat and S. G. Gouin, J. Am. Chem. Soc., 2013, 135, 18427; (d) A. Joosten, C. Decroocq, J. de Sousa, J. Schneider, E. Etamé, A. Bodlenner, T. J. Butters and P. Compain, ChemBioChem, 2014, 15, 309; (e) P. Compain, C. Decroocq, A. Joosten, J. de Sousa, D. Rodríguez-Lucena, T. D. Butters, J. Bertrand, R. Clément, C. Boinot, F. Becq and C. Norez, ChemBioChem, 2013, 14, 2050.

9 J. Diot, M. I. García-Moreno, S. G. Gouin, C. Ortiz Mellet, K. Haupt and J. Kovensky, Org. Biomol. Chem., 2009, 7, 357. 10 (a) G. D'Adamio, C. Parmeggiani, A. Goti, A. J. MorenoVargas, E. Moreno-Clavijo, I. Robina and F. Cardona, Org. Biomol. Chem., 2014, 12, 6250; (b) E. Moreno-Clavijo, A. T. Carmona, A. J. Moreno-Vargas, L. Molina, D. W. Wright, G. J. Davies and I. Robina, Eur. J. Org. Chem., 2013, 7328; (c) A. Joosten, J. P. Schneider, M. L. Lepage, C. Tarnus, A. Bodlenner and P. Compain, Eur. J. Org. Chem., 2014, 1866; (d) M. Marradi, S. Cicchi, F. Sansone, A. Casnati and A. Goti, Beilstein J. Org. Chem., 2012, 8, 951.

11 C. Decroocq, A. Joosten, R. Sergent, T. Mena-Barragán, C. Ortiz Mellet and P. Compain, ChemBioChem, 2013, 14, 2038.

12 I. Nierengarten and J.-F. Nierengarten, Chem.-Asian J., 2014, 9, 1437.

13 F. Cardona, G. Isoldi, F. Sansone, A. Casnati and A. Goti, J. Org. Chem., 2012, 77, 6980.

14 (a) J. M. de La Fuente, A. G. Barrientos, T. C. Rojas, J. Rojo, J. Cañada, A. Fernández and S. Penadés, Angew. Chem., Int. Ed., 2001, 40, 2257; (b) A. G. Barrientos, J. M. de La Fuente, T. C. Rojas, A. Fernández and S. Penadés, Chem.-Eur. J., 2003, 9, 1909; (c) J. M. de La Fuente and S. Penadés, Biochim. Biophys. Acta, Gen. Subj., 2006, 1760, 636.

15 M. Brust, M. Walker, D. Bethell, D. J. Schiffrin and R. Whyman, J. Chem. Soc., Chem. Commun., 1994, 7, 801.

16 (a) A. G. Barrientos, J. M. de la Fuente, M. Jiménez, D. Solís, F. J. Cañada, M. Martín-Lomas and S. Penadés, Carbohydr. Res., 2009, 344, 1474; (b) B. Thygesen, J. Sauer and K. J. Jensen, Chem.-Eur. J., 2009, 15, 1649.

17 M. Marradi, F. Chiodo, I. García and S. Penadés, Chem. Soc. Rev., 2013, 42, 4728.

18 While this work was in progress, two conceptually related approaches that also permit to tune the percentage of the bioactive iminosugars were accomplished by micellar selfassembly of 1-deoxynojirimycin (DNJ) based glycopeptides and by polymeric dextrans coated with DNJ and 1- 
deoxymannojirimycin (DMJ), respectively: (a) C. Bonduelle, J. Huang, T. Mena-Barragán, C. Ortiz Mellet, C. Decroocq, E. Etamé, P. Compain and S. Lecommandoux, Chem. Commun., 2014, 50, 3350; (b) Y. Brissonet, S. Ladevèze, D. Tezé, E. Fabre, D. Deniaud, F. Daligault, C. Tellier, S. Šesták, M. Remaud-Simeon, D. Potocki-Veronese and S. G. Gouin, Bioconjugate Chem., 2015, 26, 766.

19 J. C. Love, L. A. Estroff, J. K. Kriebel, R. G. Nuzzo and G. M. Whitesides, Chem. Rev., 2005, 105, 1103.

20 C. Matassini, S. Mirabella, X. Ferhati, C. Faggi, I. Robina, A. Goti, E. Moreno-Clavijo, A. J. Moreno-Vargas and F. Cardona, Eur. J. Org. Chem., 2014, 5419.

21 (a) O. Martínez-Ávila, K. Hijazi, M. Marradi, C. Clevel, C. Campion, C. Kelly and S. Penadés, Chem.-Eur. J., 2009, 15, 9874; (b) D. Safari, M. Marradi, F. Chiodo, H. A. T. Dekker, Y. Shan, R. Adamo, S. Oscarson,
G. T. Rijkers, M. Lahmann, J. P. Kamerling, S. Penadés and H. Snippe, Nanomedicine, 2012, 7, 651.

22 C. Pale-Grosdemange, E. S. Simon, K. L. Prime and G. M. Whitesides, J. Am. Chem. Soc., 1991, 113, 12.

23 S. He, I. Garcia, J. Gallo and S. Penadés, CrystEngComm, 2009, 11, 2605.

24 T. Buskas, E. Söderberg, P. Konradsson and B. Fraser-Reid, J. Org. Chem., 2000, 65, 958.

25 C. D. Bain, H. A. Biebuyck and G. M. Whitesides, Langmuir, 1989, 5, 723.

26 M. J. Hostetler, J. E. Wingate, C.-J. Zhong, J. E. Harris, R. W. Vachet, M. R. Clark, J. D. Londono, S. J. Green, J. J. Stokes, G. D. Wignall, G. L. Glish, M. D. Porter, N. D. Evans and R. W. Murray, Langmuir, 1998, 14, 17.

27 C. Parmeggiani, S. Catarzi, C. Matassini, G. D'Adamio, A. Morrone, A. Goti, P. Paoli and F. Cardona, ChemBioChem, 2015, 16, 2054-2064. 